\title{
Annotation: The Psychological Development and Welfare of Children of Opiate and Cocaine Users: Review and Research Needs
}

\author{
Diane M. Hogan \\ Trinity College Dublin, Ireland
}

Published in: Journal of Child Psychology and Psychiatry. 1998, Vol. 39. No. 5. pp. 609-620. 1998

Copyright: Wiley-Blackwell

\section{Introduction}

Parental dependence on illicit drugs is a growing concern across a number of disciplines. It has implications that are at once medical, political, social, and psychological. In recent years, researchers from the U.S.A. (Austin \& Prendergast, 1991; Deren, 1986; Johnson, 1991) and the U.K. (Burns. O'DriscolL \& Wason, 1996) have called for greater attention to be paid to social and psychological, rather than solely physical, effects of parental drug use on children. In Ireland, against the backdrop of an intractable and escalating intravenous opiate problem, the issue of how children are affected by parental drug dependence is emerging as a new social and clinical concern. A recent government report, for example, recognises that children of drug users may be in need of clinical interventions and special care arrangements (Rabitte, 1996). But what form should such services take? Are these children at greater risk than other children from similar socioeconomic backgrounds for experiencing social and psychological problems? Is the nurturing environment provided to children whose parents are dependent on illicit drugs less adequate than that provided to children whose parents do not use drugs? At present research does not provide conclusive answers to these questions. Research that focuses on the effects of postnatal parental drug use on children's social and psychological well-being is strikingly scarce, with the majority of child-oriented research concentrating instead on the effects of prenatal exposure to drugs. The small amount of research that has been conducted on the care-giving environments of children of drug users has produced largely inconclusive findings.

The aims of the present paper are to review and analyse existing research on the social environments provided to children of drug users, and on the developmental outcomes for this group. A further aim is to provide pointers to gaps and shortcomings that need 
to be addressed in future research. The focus is on parental addiction to "hard drugs", namely opiates (primarily heroin and methadone) and cocaine. Studies dealing exclusively with the impact on children of prenatal exposure to drugs ${ }^{1}$ and of parental alcohol use ${ }^{2}$ are excluded, as are studies of a primary addiction to amphetamines and other illicit substances, although it is recognised that these are frequently used in addition to opiates and cocaine.

\section{Focus on Opiates and Cocaine}

Although other reviews on this topic have typically dealt with drug and alcohol use ${ }^{3}$ together (Austin \& Prendergast, 1991; Johnson, 1991 ;Mayes, 1995), there are several reasons for the isolation of opiate and cocaine use. First, the lifestyle associated with use of these drugs is likely to be substantially different from that of alcohol use, and indeed from that of a primary addiction to other drugs such as amphetamines. Families of opiate and cocaine users are more likely to be living in poverty whereas alcohol and amphetamine users are distributed across a range of socioeconomic contexts. Perhaps the most important factor differentiating between dependence on illicit drugs and dependence on alcohol is the fact that drug use is an illegal activity in itself and must be conducted secretly, whereas alcohol is legally available. Drug use, especially of opiates and cocaine, is associated with additional criminal activities and therefore parents are at risk for arrest and imprisonment. A second critical factor is that use of drugs is associated with different health risks to those of alcoholism. Intravenous drug use carries the risk of AIDS and hepatitis in addition to the risk of overdose due to uncontrolled variance in substance potency. Furthermore, because of the illegality, lifestyle, and health risks associated with opiate and cocaine use, public reactions are different from those to alcoholism, with less public advocacy and support for drug users or their families (Johnson, 1991).

Another reason to consider the influence of these substances separately is that there is a tendency for researchers to extrapolate findings from the literature on children of alcoholics, which is substantial (see Rydelius. 1997). to children of drug addicts, although there is insufficient empirical evidence to support this generalisation (Johnson, 1991). The small number of studies comparing children of alcoholics with children of drug users has yielded mixed findings. Herjanic, Herjanic. Wetzel, and Tomelleri (1978) found no significant differences between children of heroin addicts and children of alcoholics on measures of cognitive functioning and self-esteem. On

\footnotetext{
${ }^{1}$ Not all studies clearly distinguish between children exposed to drugs prenatally and postnatally. Studies dealing exclusively with physical/medical effects of drugs on the neonate are excluded from this review. Studies that do not specify whether prenatal exposure occurred are included, with a note to this effect. Also included are those studies that explicitly consider parenting and care of the child.

${ }^{2}$ Not all studies differentiate between alcohol and drug use. Those that combine these categories are noted in the text.

${ }^{3}$ The term drug use, rather than drug abuse or misuse, is employed throughout this article, as it is a nonjudgemental term. In referring to work by other authors, however, their terminology is used.
} 
the other hand, Mayer and Black (1977) found a higher incidence of child maltreatment in families of opiate addicts than in families of alcoholics. Famularo, Kinscherff, and Fenton (1992) found no association between opiate use and child abuse, but significant associations between parental cocaine addiction and child sexual abuse and between alcohol addiction and child physical abuse. At present, however, there is not enough evidence from comparative studies of addiction to alcohol or to illicit drugs to support any generalisation from one group to the other.

This is not to suggest that all parents exclusively use one category of psychoactive substance. However, although drugs and alcohol are often taken in combination, the experiences of a child growing up in the care of a drug user, whether or not he or she uses alcohol, are likely to differ in important ways from the experiences of children whose parents exclusively use alcohol. In short, there is a need to differentiate between potentially different populations in research and in developing appropriate interventions. Research on children of drug users is based on the expectation that parental drug use has the potential to affect children's psychosocial development negatively in at least three main ways: first, by depriving them of adequate physical care; second, by impeding their socio-emotional and cognitive development; and third, by influencing them to become drug users themselves. An associated expectation is that such children are in need of special services. To what extent, however, does research on children of drug users inform us as to their particular social and psychological experiences, developmental outcomes and needs, distinct from those of children whose parents do not use drugs? What theoretical models have been used to guide research in this area, and what are the principal methodological issues in conducting research with this population? These are the central questions explored in this Annotation.

\section{Research Findings}

Relative to other domains, such as parental alcohol use, little research has been conducted on the potential psychological risks to children of drug users. As a result, we know little about the parenting and care received by these children, about their experience of growing up in a household where one or both parents use drugs, or about those who have been placed in care outside the home because their parents can no longer cope. Least is known about children aged 4 to 11 (Austin \& Prendergast, 1991; Burns et al.. 1996; Johnson. 1991).

In contrast to the lack of research on child-care and parenting issues, a substantial body of literature has accumulated concerning the effects on the neonate of chemical exposure to drugs in utero. For this reason comparatively more information is available about the psychological development of infants and toddlers of drug users. There is now considerable evidence that infants prenatally exposed to heroin are at risk for elevated tension and poor concentration (Bernsten, Jeremy, Hans, \& Marcus, 1984; Regan, Ehrlich. \& Finnegan, 1987; Vorhees \& Mollnow, 1987). Prena'al exposure to cocaine is associated with a variety of physical problems, including low 
birthweight and length (Chouteau, Namerow, \& Leppert, 1988). Children of drugusing mothers are also at risk for contraction of the HIV virus either through contact with HIV-infected blood during delivery or across the placenta. Research on infants exposed to drugs in utero originates primarily in the medical field and its focus, even where it does examine psychosocial aspects of child development, tends to remain in the medical sphere. Much of the emphasis has been on physical, and to some extent cognitive, development (Keenan, Dorman, \& O'Connor, 1993; O'Connor, StaffordJohnson. \& Kelly, 1988; Ryan, Magee, Stafford-Johnson, Griffin, \& Kelly, 1983). The greater attention paid to this group may in part be explained by the relative ease of access to mothers attending medical facilities compared to a more representative sample of mothers in the larger population of drug users.

A good deal of research has also been carried out OJ adolescent offspring and siblings of drug users, primarily arising out of efforts to identify the predictors of drug problems in that group (Fawzy, Coombs, \& Gerber, 1983; Newcomb \& Bentler, 1988; Simons \& Robertson, 1989). As a result more is known about the psychosocial needs of children at either end of the spectrum of childhood than about children in the preschool through preteen years.

The small body of literature on the social and psychological development of young children of drug users falls into two broad categories-studies of parenting and care, including child abuse and neglect, and studies of child outcomes, which deal with social and cognitive development and risk of drug use.

\section{Parenting and Care}

Studies of parenting in families of drug users can be assigned to two categories, those that focus on abuse and neglect and those that examine parenting styles and parentchild relationships that are not classified as abuse. With a small number of exceptions (for example Kands J. 1990; Tarter, Blackson. Martin, Leber, \& Moss, 1993), studies of parenting by drug users primarily investigate parenting by mothers, so that we have little knowledge about the parenting provided by fathers who are drug users.

Parenting attitudes and behaviours. Under the general heading of "parenting", research has focused on parental attitudes and disciplinary styles. Inconsistency in the measures used and definitions of parenting make it difficult to identify any distinct pattern of findings across studies.

In a study of parenting attitudes, Colten (1980) compared 170 women in drug treatment facilities (including mothers who were being maintained on methadone and those in therapeutic communities) to a matched control group. No differences were found between the two groups on attitudes and expectations regarding child rearing.

However, addicted women were less likely to perceive themselves as adequate parents and had more concerns about their children becoming addicts, drop-outs, or being 
involved in crime. Wellisch and Steinberg (1980) compared addicted mothers in detoxification programmes, nonaddicted mothers, and women who were neither mothers nor addicted. They found that addicted mothers scored higher on a factor called "authoritarian over-involvement", which reflects a tendency to exclude outside influences on parenting and to try to control the child. Bauman and Dougherty (1983), however, in a study of 15 mothers on methadone maintenance and 15 drug-free mothers, found no differences in parenting attitudes, as measured by Baumrind's (1974) Parenting Attitudes Questionnaire.

Studies of parenting behaviours have also yielded mixed findings. Bauman and Dougherty's (1983) study of methadone-maintained mothers and their children used observations of parent-child interaction. Although no differences were found between this group and a control group of non-drug users on parental attitudes, differences were observed in certain forms of parental behaviour: methadone-maintained mothers were found to have a higher frequency of aversive behaviours, and specifically to engage more in commanding, disapproving, provoking, and threatening behaviour. A reliance by drug-using mothers on harsh verbal responses to children, such as yelling and strong criticism, has also been reported (Lief, 1985; Tucker, 1979).

Kandel (1990) examined the relationship between previous and current drug use and parenting styles. Using a longitudinal cohort design, a representative sample of 1222 adolescents, mostly female, in New York public high schools, were followed from age 15-16 to young parenthood (age 28-29). The focus was on the oldest child of 2 years or above. It was expected that a history of drug use would be associated with a lack of parental monitoring, low warmth, and higher levels of conflict between parents, and that children in these families would be more likely to have behavioural problems (especially in relation to obedience/control) than children whose parents did not have a history of drug use. In fact, few statistically significant relationships were found. For mothers the relationships were in the expected direction, with poorer parenting (lack of monitoring, low levels of warmth) increasing with greater drug involvement. For fathers, however, involvement with drugs was in some cases associated with reports of positive parenting, and especially to a decrease in punitive discipline and to greater involvement in activities with the child. In another study involving fathers, Tarter and his colleagues (1993) studied disciplinary practices with 10-12-year-old boys $(N=46)$ whose fathers were substance abusers, though some were alcohol rather than drug users. The overall quality of parental discipline provided in families of substance abusers was poorer than that in a control group. Although there were no differences in terms of consistency and severity of punishment, discipline was less effective in families of substance abusing fathers.

Child abuse and neglect. Studies of abuse and neglect typically aim to identify the degree and nature of the relationship between drug use and child maltreatment by estimating the prevalence of drug use in court or clinical samples of parents referred for serious child maltreatment. Again, this body of work has produced mixed findings. 
Studies of the incidence of child abuse in children receiving hospital treatment suggest that children of drug users may be at risk for neglect-related disease and for maltreatment. Casado-Flores and associates (Casado-Flores, Bano-Rodrigo, \& Romero. 1990) studied 75 children who had been born to parents, one or both of whom were addicted to intravenous heroin. Seven of the children had been exposed prenatally to illicit drugs. All children had been patients at a children's hospital in Madrid and the study involves retrospective analysis of their hospital records. The authors found that, compared to children of non-heroin-addicted parents, this group was more prone to developing illnesses. The most common of these were infectious and nutritional diseases, and those related to parental neglect or disinterest. The authors note, however, that outcomes may be explained by the fact that more than $50 \%$ of the mothers were teenagers. Evidence of greater risk to children of drug-using parents was also found by Wasserman and Levanthal (1993). They compared the rearing environments of children whose mothers had used cocaine during pregnancy to a sociodemographically matched group of mothers who had not. Using a retrospective cohort design (two groups born in the same hospital during the same period) they looked at the incidence of maltreatment of children in each group by classifying all recorded injuries to the children as evidence of abuse (sexual or physical), neglect, unintended injury, and household or neighbourhood violence. The rater was blind to the drug use of the mother. Children of cocaine-using mothers were at a substantially higher risk of maltreatment $-23 \%$ had experienced at least one episode of maltreatment by age 24 months, compared to $4 \%$ of the control group. The rates of unintentional injury were similar. Sowder and Burt (1980) compared 365 children (aged 3-17) of treated heroin addicts to 369 children from the same neighbourhoods.

They also found greater evidence of child abuse among drug-using parents; rates of abuse were 10 to 15 times higher than rates calculated for parents across the U.S. However, the comparison group of families from the same neighbourhoods and of similar (low) socioeconomic status also had exceptionally high rates of abuse, indicating that poverty may be at the root of the problem.

Studies using court samples to determine prevalence of abuse and neglect also suggest an association between drug use and child maltreatment. Murphy and associates (1991) used a court sample of cases referred for child abuse over a 2-year period, and found that in $43 \%$ there was evidence of substance abuse (alcohol and illicit drugs) by parents. Fourteen per cent of mothers and $7 \%$ of fathers were defined as exclusively drug abusers. Parents who were substance abusers were more likely to have been referred previously on child mistreatment charges and to reject court-ordered services.

The study was correlational, and therefore no causal relationship could be demonstrated. Furthermore, since the design did not compare the target sample to a sociodemographically matched sample, the possibility of a spurious relationship 
between child maltreatment and substance abuse is substantial. The sample was characterised by high levels of poverty, lack of social support, low education, and parental history of being mistreated as a child. Substance abuse, therefore, may simply be a co-occurring effect caused by an underlying factor. Similarly, Famularo et al. (1992) reviewed 190 randomly selected court records over a 3-year period with the goal of identifying a link between substance abuse (documented by professionals) and child maltreatment. All cases were of children taken into care due to parental maltreatment - physical or sexual. While cocaine abuse was strongly associated with sexual abuse (49\% of parents who committed sexual abuse were cocaine users) and alcohol abuse was associated with physical maltreatment (46\% of these parents used alcohol), there was no significant association between opiate use and either type of maltreatment. Furthermore, neither form of maltreatment was associated with the combined effects of more than one kind of substance abuse. No attempt was made to control for socioeconomic status or to look at other explanatory factors.

Mayer and Black (1977) compared 100 opiate and 100 alcohol-dependent parents receiving treatment, all of whom had a child in their care during the previous 6 months. They reported that certain or probable abuse of at least 1 child had occurred in 10 families (13\%). Nine of the 10 were families of drug addicts and 1 was a family of an alcoholic. All families of drug addicts were living under stressful conditions, including unemployment and poverty. However, in a later study comparing alcohol and opiate-addicted parents no differences were found in the rates of abuse and neglect (Black \& Mayer, 1980).

Studies on the likelihood that children of drug users will be placed in care outside the home and their experiences of such care are scarce. There is evidence, however, that the experiences of children of drug addicts in care are different from those of other groups. Fanshel (1975), in a study of children of heroin-addicted mothers using a sample of children in care, found that children of drug-using mothers tended to enter care earlier than other children and to stay longer. Indeed, drug use by mothers was the strongest predictor of tenure in foster care. When discharged from care, moreover, the majority did not return to their mothers, but to relatives or friends.

Overall, these studies indicate that children of drug users may be at risk for abuse and/or neglect. However, they are seriously limited by the exclusive use of retrospective data obtained from preselected samples. With few exceptions (for example, Sowder \& Burt, 1980), this literature provides no information about children who have not been hospitalised, whose parents have not been referred to the courts on charges of abuse, or who are not in care outside the home. They inform us only about those families who have come to the attention of health and welfare authorities and therefore findings cannot be generalised beyond these groups. This literature underscores the importance of including community samples in studies of children at risk. It also highlights the need to include demographically matched control groups, since it is currently impossible to separate the contribution of drug dependence to 
child abuse and neglect from the contribution of other factors that typically co-exist with problem drug use, such as unemployment or poverty.

The above studies of the care and welfare of children, broadly speaking, point to diversity within the population of drug users in the impact of drug misuse on their capacity to care for their children, depending on several factors. One factor is the type of drug used; opiate use appears to affect parenting differently than does cocaine use. It is equally plausible that the quality of parenting and incidence of child maltreatment varies with other drug-related factors, such as duration of addiction, types of treatment obtained, history of efforts to abstain from drugs, and so on.

It is also important to note that associated factors in addition to drug use can predict parenting impairment. In two studies of psychological well-being, psychosocial resources, IQ, and SES in conjunction with drug use predicted poor-quality interactions by opiate-dependent mothers with their children although drug use alone did not (Jeremy \& Bernstein, 1984; Johnson \& Rosen, 1990). The existence of comorbid psychiatric disorders may also contribute to impairment of parenting. It is well established that many opiate users enter treatment programmes with a co-existing psychopatholrgy (Rounsaville \& Kleber, 1985) and that it is also common for cocaine users to present for treatment with psychiatric symptoms (Rounsaville et al., 1991).

The relationship between drug misuse and comorbid psychopathological symptoms is complex (Ziedonis, 1992), in that it is difficult to ascertain whether drugs have been used to medicate psychiatric symptoms or whether psychiatric symptoms developed from the physiological effects and lifestyles associated with drug use (Luthar, Anton, Merikangas, \& Rounsaville, 1992; Zuckerman, Amaro, Bauchner. \& Cabral, 1989). In either case, it is important to recognise that high rates of depression, phobias, generalised anxiety disorders, and mood disorders have been found among treated opiate users (Rounsaville, Weissman, Kleber. \& Wilber, 1982; Williams, O'Connor, \& Kinsella, 1990), although nontreated opiate users appear to have lower levels of depression (Maddux. Desmond, \& Costello, 1987; Rounsaville \& Kleber, 1985). Affective disorders are also significant in cocaine users (Weiss, Mirin, Michael, \& Sollagub, 1986). Furthermore, comorbid psychiatric disorders may be associated with greater parenting difficulties among drug users than non-drug users (Mayes, 1995).

\section{Child Outcomes}

Findings regarding the social and psychological effects of parental drug use on children have varied. Some studies report few or no differences between children of drug users and comparison groups on behavioural adjustment (Fanshel. 1975), on intelligence (Bauman \& Levine, 1986), or on developmental progress (Burns et al., 1996); others have found children of drug users to compare poorly to control groups on aversive behaviour (Bauman \& Levine, 1986), on difficulty of temperament (Tarter et al., 1993), on socially adaptive behaviour (Bauman \& Dougherty, 1983; Kandel, 1990: Tarter et al.. 1993), and on control problems (Kandel, 1990). 
Social development. Research on personality, psychosocial competence, and affect in children of drug users is rare. As Johnson (1991) points out, however, it is critical that this area is addressed, given the reportedly high incidence of mood and anxiety disorders among opiate users (Maddux et al., 1987; Rounsaville \& Kleber. 1985). There is some empirical evidence that children of drug users have difficulties in the area of socioemotional development. Bauman and Levine (1986) found that preschoolers of methadone-maintained mothers were more impulsive, immature, and irresponsible than children of non-drug users. A study by Wilens and his colleagues (Wilens, Biederman, Kiely, Bredin. \& Spencer, 1995) also points to elevated rates of emotional and behavioural problems. Children (aged 4-18) of methadone-maintained parents were compared to children with attention-deficit hyperactivity disorder plus comorbid psychiatric disorders, and a control group of children without psychological disorders. Compared to controls, children of opiate-dependent parents had significantly higher levels of internalising and externalising behaviours on the Child Behavior Checklist (Achenbach, 1991). Kandel (1990), on the other hand, found mixed support for a hypothesised relationship between child behavioural characteristics and parental drug use. It was supported only for maternal drug involvement, with higher drug involvement associated with a decrease in obedience of children, and an increase in their aggressive, withdrawn, and detached behaviour. For paternal drug use relationships were not as strong, and in some cases were in the opposite direction to those hypothesised. The results suggest a greater role of mothers than fathers in child rearing and provides some support for a link between child behaviour and parent drug use, especially in the area of control. Johnson, Boney, and Brown (1991) also found evidence that children of drug users are at higher risk for symptoms of depression and trait anxiety than children of non-drug users, based on the Children's Depression Inventory (Kovacs, 1983) and the How I Feel Questionnaire (Speilberger, 1973), although children did not meet the criteria for clinical diagnoses.

There is also some evidence that children of drug-dependent parents have more problems with peer relations. According to Kumpfer and DeMarsh (1986), such children have fewer friends to play with and to confide in, lower confidence in their ability make friends, and experience greater avoidance by peers. However, the authors do not distinguish between children whose parents used drugs from those whose parents were addicted to alcohol (Austin \& Prendergast, 1991). Studies of children in care have also produced varied results. Nichtern (1973) observed that among children of drug users there appeared to be a higher incidence of disturbed social behaviour: "Most of the children appeared to manifest some problem with their capacity for human relatedness" (p. 29). He noted a distinct pattern of anxiety in social interaction, evidence of withdrawal, and poor responsiveness. In stark contrast, the work of Fanshel (1975) suggests that children who are in care due to parental (usually mothers') drug use are less impaired developmentally than children in care for reasons not related to drug use. and indeed perform better in some areas. Children of drug users tended to be more agreeable, less withdrawn, and less tense than other children 
in care, though not significantly so. This may be due to the fact that the children of drug users were in care from a younger age. At entry into care, such children had significantly fewer emotional problems.

Cognitive development. In the area of cognitive development and school progress the number of studies is also small, but the evidence of problematic child outcomes is more compelling. In research conducted by Fanshel (1975), there was no evidence of poorer cognitive performance by children of drug users compared to other children in care, but teacher ratings indicated poorer school adjustment. In contrast, Nichtern (1973) found that children in care due to parental drug use experienced delays in the development of speech and learning problems at school, although with no discernible pattern, but it is not known whether the children in the study were exposed to drugs prenatally. Sowder and Burt (1980) found that children of heroin-addicted fathers were at greater risk for poor school progress, both learning and behavioural, than control children from the same neighbourhoods. They had lower IQ and perceptualmotor performance and greater need for remedial teaching. They also had more behavioural problems at school, missed more days, and were more likely to have their parents contacted due to child misbehaviour. Children in the control group also had problems, but to a lesser degree. In another study of children of heroin-addicted fathers a similar pattern was found (Herjanic, Barredo, Herjanic, \& Tomelleri, 1979), with $42 \%$ of children of heroin addicts studied exhibiting slow mental development. Johnson and her colleagues (1991) reported that children of substance abusers scored significantly lower than children of non-substance abusers on the arithmetic scale of the Wide Range Achievement Test (Jastak \& Wilkinson, 1984), but not significantly so on either reading or spelling. Finally, in both a small-scale study (Bauman \& Dougherty, 1983) and subsequently a larger-scale replication (Bauman \& Levine, 1986), preschoolers of methadone-maintained mothers performed significantly worse (though still in the normal range) on the Stanford-Binet intelligence test than did a control group of children of non-drug users.

The above studies exclusively compare children of drug users with those of non-drug users. A more complex picture emerges, however, when a distinction is made between those exposed prenatally to drugs with those who were not. Wilson and her colleagues (Wilson, McCreary, Kean, \& Baxter, 1979), using a comprehensive psychological battery of tests, compared children exposed to heroin in utero, children who were not exposed in utero but whose mothers were drug users, members of a high-risk group (birth complications due to medical problems), and a socioeconomically matched group. The first group, those exposed prenatally, performed significantly worse than all other groups on physical, intellectual, sensori-motor, and behavioural measures. Children whose mother was a drug user performed slightly better than those prenatally exposed, but significantly less well than the remaining two comparison groups. These findings call into question the validity of earlier study outcomes where mothers' prenatal drug use was unknown. More important, perhaps, Wilson's study provides 
compelling evidence that, although there is a biological effect arising from prenatal exposure, there is also a strong effect for the child-rearing environment.

Much like the literature on social development, the literature on cognitive development of children of drug users lacks cohesion, direction, and a clear basis in either previous literature or theory. The existing literature does not address the issue of interaction between chemical/ prenatal exposure to drugs and the conditions in the postnatal environment. Neither does it address the role played by parental cognitive ability and the potential for children's lower performance in cognitive tests to be explained by genetic influences. Most importantly, however, it lacks baseline information on a number of issues directly related to parental drug use, such as the daily impact on the organisation of children's school-related activities.

Drug use by children. In contrast to other issues reviewed here, there is comparatively clear evidence in the international literature that problem drug use by parents is associated with drug use by their children (Fawzy et al., 1983; Gfroerer, 1987; Sowder $\&$ Burt, 1980). Several studies conducted in the 1970s found that adolescents whose parents or a significant other used or were perceived to use drugs were likely to use drugs themselves (Kumpfer \& DeMarsh, 1986), and this has been supported by more recent work. Gfroerer (1987) found that teenagers are more likely to use marijuana if a parent or older sibling does so, and Fawzy et al. (1983) report similar findings. However, the reasons for this association have not been adequately explored (Austin $\&$ Prendergast, 1991). In particular, there is confusion over the relative role of biological/genetic factors and environmental factors and of the weight to be attached to each of these areas of influence. Research on environmental factors indicates that parental attitudes to drug use may be as important an influence on drug use by adolescents as actual parental use (Barnes \& Windle, 1987). The effects of socioeconomic factors relative to parental influence have not been identified and therefore future research should seek to establish the relative contribution of these factors. Adolescent use of opiates appears to be confined to the same geographical regions as in previous generations (O'Higgins, 1996), but more work needs to be directed at tracing family continuity of drug use.

\section{Individual Differences in Parenting and Child Outcomes}

The studies reviewed here provide a clear indication of the nature of research on children exposed to parental drug use postnatally: there is little of it, it lacks direction and cohesion, and the findings are at best inconclusive, at worst contradictory. It is almost impossible, therefore, to point with certainty to the kinds of difficulties experienced by children of drug users, or to the degree to which those problems are experienced across different family situations. One finding that cuts across these different foci of research, however, is that individuals, both parents and children, react differently in the face of adversity, some exhibiting more resilience than others. 
One critical protective factor differentiating between individual parents' ability to cope and individual children's psychological well-being appears to be social support. Although research in this area is limited, there are indications that psychosocial difficulties in children of drug users may be explained at least in part by social isolation. Families of drug users experience greater levels of community rejection and are less involved in several areas of social life, including religious, neighbourhood, and cultural activities (Kumpfer \& DeMarsh, 1986). This may be particularly true for women. Tucker (1979) reported that addicted women were particularly at risk for loneliness and isolation, and inadequate social support. He compared the social support networks of women in heroin treatment programmes with men in these programmes and with a control group of women. Addicted women were more likely to report that they had no friends, experienced feelings of loneliness, and received less emotional support from friends than either of the other two groups. Anecdotal evidence suggests that grandmothers provide essential support in terms of childcare that may be an important factor in preventing parenting breakdown. Research in other domains has shown that the effects of stress on parenting can be moderated by social support, thereby reducing the risks to children (Rutter, 1990). Further work is necessary to identify the primary source of social support to families of drug users, and the kinds of support that parents and their children view as most important.

In addition to the prevailing difficulties of poverty that frequently add to the burden of drug dependence and render both parents themselves and their children more vulnerable to experiencing psychological problems, many drug-using parents appear to have experienced adversity in their families of origin as well as with their own spouses or partners. Many drug-using women report having been abused as children and female drug users experience a high incidence of physical abuse as adults. In one study $70 \%$ of women attending treatment centres had been beaten as adults, $86 \%$ of these by husbands or partners (Regan et al., 1987). This kind of contextual information may help to explain why some mothers experience feelings of inadequacy and adopt inappropriate parenting styles, yet studies of drug-using parents typically fail to provide information about the target parent's spouse or partner. Information on the drug behaviour of the spouse is also needed in that, when both parents are involved in drug use, the childrearing environment may be significantly different from that when only one parent is involved.

\section{Methodological Issues}

The lack of clear and consistent findings about the psychological consequences for children of parental drug use may be attributable in part to a number of methodological restrictions evident in the literature. Two main categories of methodological problems can be identified - those related to definition of terms and categories, and those related to lack of control in the design Two subcategories of definition issues can be identified. 
Definition of type of exposure to drugs-prenatal vs. postnatal. Lack of clarity regarding the nature of children's exposure to drugs can confound the effects of prenatal exposure and environmental factors. The paucity of research on postnatal social exposure, as distinct from prenatal chemical exposure to parental drug use may be due to the difficulty associated with identifying reliably those children who were prenatally exposed and those who were not. Certainly, it is easier to identify those exposed prenatally, particularly if mothers make their use of drugs known to medical staff around the time of birth. It is substantially more difficult to rule out maternal drug use during pregnancy retrospectively once mother and child have left the hospital and any physical traces of drugs in the child have disappeared. It is difficult to estimate the reliability of mothers' own reports of their drug-taking behaviour during pregnancy since they may be deterred by fears of being labelled as an unfit parent. It is important, however, that such a distinction is made and that greater precision is used in defining the nature of children's exposure to drugs, as evidenced by a study comparing the developmental outcomes of children of methadone-maintained mothers to children of non-addicted mothers (Bauman \& Levine, 1986). When children born with withdrawal symptoms were considered separately an effect for withdrawal was demonstrated - these children scored lower on MCDI development scales, IQ, motor development scales, and height and weight than children who had not been prenatally exposed but raised by a drug-addicted mother. The distinction is also important because physical exposure may give rise to physiological and temperamental patterns in children that elicit negative parental responses (Griffith \& Freier, 1992).

\section{Definition of nature of parental drug use. A preponderance of different and unclear} definitions of drug use across studies is a further cause of confusion. For example, can poly-drug use be expected to have equivalent effects on parenting as one specific drug? Can mothers receiving methadone treatment be assumed to be typical of all heroin-using mothers? Precision is often difficult, since drug users' patterns of drug taking and adherence to medication programmes vary. Furthermore, it may be difficult to differentiate between methadone-maintained and current opiate users, since drug users may be taking both methadone and heroin. There are also differences among drugs in their physiological and psychological effects (Khantzian, 1985) that have implications for a user's ability to care for a child (Famularo et al., 1992). Heroin and anti-anxiety drugs, as well as alcohol, tend to cause depressed mood, whereas cocaine and amphetamines are stimulants and are associated with increased activity and agitation. Both categories of drugs may impair parental responsiveness and attunement to children and influence clinical intervention (Mayes, 1995). The psychological effects of the degree and duration of drug use and treatment and their implications for stability of lifestyle and parental dysfunction must be addressed. Drug users differ in the consistency and extent of their drug use and not all can be considered to be addicted (Glantz \& Pickens, 1993). Therefore it must be acknowledged that the consequences for parental functioning and involvement in the drug culture will also vary and have different consequences for the life experiences of their children. 


\section{Exclusive Use of Clinical or Other Preselected Samples}

This is perhaps the most critical and difficult methodological issue facing researchers, since identification of and access to participants is restricted to a large extent by the illegal nature of drug use. There is clearly a need for evidence from nonclinical samples in order to assess the magnitude of risk to which children are exposed. The majority of studies of children of drug addicts, however, recruit parents attending drug treatment facilities. Clearly the extent to which these parents and their children can be considered to be representative of those not connected to drug treatment facilities is questionable. It is generally accepted that there is a greater incidence of pathology in clinical samples (Johnson, 1991). However, the opposite effect may occur in the case of drug use, in that attendance at treatment facilities may indicate greater stability and self-control, which may also be manifest in more stable and improvement-oriented parenting practices (Burns et al., 1996). In one study comparing addicted mothers both in and out of treatment, 67 children of narcotic addicts were compared to 57 controls through their first year of life. Over a third of the children of addicts were no longer in the care of their mothers at the end of the first year and the majority were children of mothers not receiving treatment (Lawson \& Wilson, 1980). On the other hand, the likelihood of a co-morbid diagnosis of depression appears to be greater among treated than non-treated opiate users (Rounsaville \& Kleber, 1985), which may indicate that those who seek treatment, or specific subgroups of those in treatment, are experiencing greatest psychological distress. Other researchers of child abuse and neglect use court samples or cases reported on allegations of child abuse and neglect (Murphy et al., 1991). Here, the frequency and severity of the problem may be overreported.

Another aspect of this problem is an almost exclusive focus on children in out-ofhome care. Although it is valid to compare the histories of children in care because of parental drug use to those in care for other reasons (Fanshel, 1975), findings cannot be generalised beyond children in care. Children who remain in the care of their parents or are informally placed with friends or relatives may experience quite different trajectories.

\section{Failure to Include a Comparison Group Matched on Relevant Socioeconomic Variables}

Serious drug-dependence problems are frequently associated with low socioeconomic status and socially disadvantaged living conditions. Failure to include an appropriately matched sample risks confounding parental drug use with socioeconomic status and precludes reaching meaningful conclusions about the separate effects of a drug-using lifestyle and social deprivation. In turn, it restricts efforts to identify children's special needs arising out of parental drug use. For example, Bauman and Dougherty (1983) compared methadone-maintained and non-drug-using mothers and found that methadone-maintained mothers were less adaptive and exhibited more aversive 
behaviours. However, the non-drug-using mothers had significantly higher levels of education, which confounds this conclusion.

\section{Failure to Include Control Groups Matched on Age and Gender}

Other potentially confounding factors such as child age and gender must also be held constant. Combining children of a very wide age range in a single group may mask developmental difference in the effects of parental drug use. Research in the U.S. (Werner \& Smith, 1992) indicates that children react differently to stressors depending on their age and gender, and that different factors serve as risk and protective factors. For example, boys under age 10 have been found to be more vulnerable to negative life events whereas girls are more vulnerable in adolescence. A group capturing ages 4-18 may find no effects on average, but simply because, in looking at the whole age range, the effects have become "lost" statistically.

\section{Conceptual Issues}

The literature on children of drug users generally lacks explicit theoretical foundations. This is reflected in the lack of cohesion in, and framing of, approaches to research. In the absence of guiding and explicit conceptual models, research questions and hypotheses are drawn from a fragmented and disparate literature base. They are also drawn from the literature on children of alcoholics, which indicates that parental alcoholism has negative effects on children's interpersonal relationships (Austin \& Prendergast, 1991; Cork, 1969; Johnson, 1991). However, given the lack of empirical evidence regarding children of drug users, the grounds for such generalisations must be questioned. In addition, research appears to be guided by popular assumptions about the nature of drug users, which are often contradictory. For example, despite the absence of supporting data, it is frequently assumed that parents who are drug users are either unable or unwilling to provide adequate care for their children, and that such children are at greater risk for physical and sexual abuse and neglect. A number of authors argue that use of illicit drugs by parents in itself constitutes evidence of inadequate parenting (Murphy et al., 1991; Neville, McKellican, \& Foster, 1987). Densen-Gerber and Rohrs (1973) argue that parental drug addiction, by definition, takes precedence over the child's basic needs and that therefore such children are at risk for maltreatment. Fanshel (1975, p. 608) assumes that drug-addicted parents lead a "sociopathic lifestyle", but fails to provide empirical evidence to support this claim. Likewise Casado-Flores and associates (1990, p. 978) propose that there is a typical drug-addict personality, one that is characterised by "impulsivity, irresponsibility, immaturity and self-centredness." Others suggest that children of drug users should be placed in foster or residential care rather than be allowed to remain in the care of a drug-addicted mother (O'Connor et al.. 1988).

Two implicit models of individual addiction underlie these assumptions. One is the model of drug addiction as personality defect. This model assumes that addicts share certain personality characteristics: for example, the opiate addict is viewed as chaotic and unstable (Craig, 1982). It assumes a biological disposition to drug dependence. A 
second and related model is that of drug dependence as disease (Peele, 1989). This model views drug dependence as progressing in a linear fashion, deteriorating until medical treatment and/or detoxification is sought. Ii suggests that individuals have lost control of their own behaviour and implies that the addiction exists to some degree independently and externally determines the addicts' behaviour. The typical image associated with this model is the drug addict who is concerned solely with acquiring drugs to the detriment of child welfare. The practical consequence of accepting these models and their associated assumptions is that children of drug users tend to be more carefully scrutinised than those of non-drug users. International studies indicate that they are more likely to be hospitalised for common childhood illnesses and for minor illnesses than are children of non-drug users, and to have their discharge from hospital delayed because medical staff are concerned about parental ability to provide care and to cope with stress (Casado-Flores et al., 1990; Wilson et al., 1979). In the U.S., drug users are more likely to have their children permanently removed into care by the courts, especially if they use heroin or cocaine, and to be given fewer chances to prove their adequacy as parents before such a removal than parents who are addicted to alcohol (Murphy et al., 1991). In addition, mothers who are known drugs users are more likely to be reported to child welfare authorities for minor injuries to the child than are other mothers (Wasserman \& Levanthal, 1993).

These models are also problematic for research. The central problem is that they focus on drug users as individuals affected by, or controlled by, their dependence on drugs. They fail to focus on drug users as parents, and therefore provide no explanatory link between parental drug use and child outcomes. In addition, because they are biologically and individually oriented, they are overly simplistic, ignoring the sociocultural and political contexts of drug use and the complexity of factors giving rise to and maintaining this. They also fail to recognise contextual factors such as social support that may mediate the risks to children. Finally, they emphasize deficit rather than competence, perhaps guiding researchers to seek evidence of inadequacy.

\section{Future Research Needs}

\section{Developmental Context}

Children of drug users are raised in social contexts that may differ from children of non-drug users in a number of ways. First, children are exposed, directly or indirectly, to the risky lifestyle associated with opiate and cocaine use. In order to assess the effects on children of this exposure, researchers must examine whether, and the degree to which, children witness the activities surrounding drug taking, such as oral ingestion, smoking, and injecting, the paraphernalia used in drug taking, and conversations about drugs. The family home may be used as a gathering place for other drug users, and the potential effects on the home environment may have important implications for children's welfare and development. Future research should look at the impact of this exposure on children's knowledge of, and attitudes to, drugs. 
A second way in which parental drug use may alter the developmental context relates to the illegal nature of drug use and its close correspondence with other criminal activities. Some drug users become involved in supplying drugs as a means to pay for a personal supply, while others restrict their criminal activity to shoplifting and other robberies (O'Dea, 1996; O'Mahony, 1996). There are potential implications for the effects on children's moral development of the role model provided by parents who engage in such activities (Johnson, 1991; Sack, Seidler, \& Thomas, 1976), in that these may expose children to the legal system in potentially harmful ways. For example, children may witness parents being arrested, in conflict with police, and in prison. They may overhear conversations about crime and imprisonment. Exposure of this type may negatively affect social development, particularly attitudes to authority and crime, and may result in children having inappropriate knowledge about criminal activity. There is at present little research on the pro-social development of children of drug users. Research on this topic should include measures of aggressive and antisocial behaviour and of peer relations as well as assessing children's knowledge of and attitudes to crime and the legal system.

The illegality surrounding drug use may also affect the consistency of the rearing environment for children. Drug-using parents may be absent from the home more frequently, due to imprisonment, than is the case with non-drug-using parents, perhaps resulting in children's placement in out-of-home care. It is important that research is conducted on the extent of such forced separations and their effects on parent-child relationships in this population.

Furthermore, the home environment may be affected by the concealment necessarily involved in the illegality of drug use. Parents who use illicit substances cannot do so openly, and may try to hide their drug activities, perhaps excluding children from certain rooms in the home. Parental fears of discovery may lead to an atmosphere of secrecy and children may become fearful of revealing inappropriate information either to other family members or individuals outside the family. In the resulting atmosphere of tension and anxiety, children may become withdrawn and uncommunicative.

Research should therefore continue to investigate whether children of drug users display internalising behaviours to a greater extent than children of non-drug users and to explore other outcomes of family secrecy. In particular, children's vulnerability to isolation and loneliness must be examined.

The context of children's development may also be affected by the health problems associated with opiate and cocaine use. As a group, children of drug-using parents, and especially children of intravenous drug users, may be exposed to greater risk of experiencing bereavement and loss. They may be more likely than their peers from similar social backgrounds to lose one or both parents due to death from drugs-related illnesses. In addition to the reality of bereavement, such children may be exposed to fears of parental death through AIDS, hepatitis, overdose, or poisoning. Parents may be absent from the home periodically for treatment purposes. For these reasons, the 
areas of childhood bereavement and the incidence of depressive and anxiety disorders in children of drug users are in need of urgent attention. The broader social context of children's development may also be altered by parental use of opiates and cocaine. Given the predominance of drug use in economically and socially deprived areas, most of these children live under conditions of disadvantage. Parental drug use may exacerbate these already negative circumstances if, for example, family income is used to purchase drugs. Disapproval, current drug use, and/or a history of conflict within their parents' families of origin may detract from the availability of social support. Negative social attitudes to drug use may also lead to children being ostracised in their communities and schools. Teacher's expectations and attributions about the abilities of children known to have drug-using parents, and the reaction of their peers, may affect children's social relationships and their academic progress. Future research must assess the availability of support to such children in assessing their needs and designing intervention strategies.

\section{Parenting Process}

As well as altering the context in which children are raised, drug use by parents has implications for the dynamics of parenting in day-to-day life. Research on parenting competencies of drug users has explored the issues of parental knowledge and attitudes as well as aversive behaviours, discipline, monitoring, warmth, and involvement. It has not succeeded, however, in explicitly linking those elements of parenting behaviours with drug use. Future research may explain this link by relating altered parental behaviour to changes in the parenting context, as described earlier, and to the direct impact of drugs on the individual functioning of parents. If, for example, drug-using mothers monitor their children to a lesser extent than non-drugusing mothers, as Kandel's (1990) work suggests, can this be explained by factors specifically related to their drug use? Are such mothers preoccupied with obtaining drugs or money for drugs? Can their lower levels of child monitoring be explained by physiological changes resulting from the recent consumption of drugs or by withdrawal from drugs? Or perhaps these differences can be explained by variation in the levels of social support available to drug-using and non-drug-using mothers? In terms of child development, it has been found that children of drug users perform less well at school than other children. Anecdotal evidence suggests that their school progress may be inhibited by inadequate help with homework and low parental value for, and involvement in, education, yet this is rarely investigated. Even less is known about the process by which drug use influences levels of parental involvement in children's daily lives, or indeed how this may differ for mothers and fathers. Future research must look at how parental involvement and other aspects of parenting are affected, both directly and indirectly, by their use of drugs, and how these, in turn, influence children's activities and relationships.

This is not an exhaustive list of the ways in which opiate and cocaine use may impinge, directly or indirectly, on the ability of mothers and fathers to provide adequate care to children. Exploratory research, using qualitative methodology, can 
contribute to identification of further research needs by revealing parents' and children's own perspectives on how parental opiate and cocaine use affect children's lives. Such studies can be used to develop appropriate conceptual models, and can thus contribute to identifying future research needs.

\section{Conclusions}

The limited amount of empirical evidence currently available suggests that children of drug users may be at risk for a variety of problems but that further research into this area is needed. Researchers must explicitly adopt conceptual frameworks that allow for consideration of social-contextual as well as individual influences, and which bring together issues of parenting, child development, and child care with those of drug use. Such frameworks facilitate identification of research questions and suggest testable hypotheses. Clear research plans must be combined with methodologically appropriate designs and instruments. In this way, useful answers can be obtained to the question posed earlier: Are children of drug users at risk, and, if so, what is the nature of that risk? 
Acknowledgements - I am grateful to Dr Martin Fellenz, Mr Robbie Gilligan, and Dr Sheila Greene, of Trinity College Dublin, for their helpful comments on earlier drafts of this paper.

\section{References}

Achenbach, T. M. (1991). Manual for the Child Behavior Checklist/4-18 and 1991 Profile. Burlington, VT: University of Vermont Department of Psychiatry.

Austin, G., \& Prendergast, M. (1991). Young children of substance abusers. Prevention Research Update, 8, 1-69.

Barnes, G. M., \& Windle, M. (1987). Family factors in adolescent alcohol and drug abuse. Drug and Alcohol Abuse in Children and Adolescence Pediatrician, 14, 13-18.

Bauman, P. S.. \& Dougherty, F. E. (1983). Drug-addicted mothers' parenting and their children's development. The International Journal of the Addictions, 18, 291-302.

Bauman, P. S., \& Levine, S. A. (1986). The development of children of drug addicts. The International Journal of the Addictions, 21, 849-863.

Baumrind, D. (1974). Parental Attitudes Questionnaire. Unpublished questionnaire, Institute of Human Development, University of California at Berkeley.

Bernstein, V., Jeremy, R. J., Hans, S. L., \& Marcus, J. (1984). A longitudinal study of offspring born to methadone-maintained women. II. Dyadic interaction and infant behavior at 4 months. American Journal of Drug and Alcohol Abuse, 10, 161-193.

Black, R., \& Mayer. J. (1980). Parents with special problems: Alcoholism and opiate addiction. Child Abuse and Neglect, 4, 45-64.

Burns, E C, O'Driscoll, M., \& Wason, G. (1996). The health and development of children whose mothers are on methadone maintenance. Child Abuse Review, 5, 113-122.

Casado-Flores. J.. Bano-Rodrigo, A.. \& Romero, E. (1990). Social and medical problems in children of heroin-addicted parents: A study of 75 patients. American Journal of Diseases in Children. 144, 977-979.

Chouteau, M., Namerow, P. B.. \& Leppert, P. (1988). The effect of cocaine abuse on birth weight and gestational age. Obstetrics and Gynecology, 72, 351-354.

Colten. M. E. (1980). A comparison of heroin-addicted and non-addicted mothers: Their attitudes, beliefs and parenting experiences. NIDA, Services Research Report, Heroinaddicted parents and their children; Two reports. DHHS Pub. No. (Adm) 81-1028.

Cork, M. (1969). The forgotten children. Toronto: Addiction Research Foundation.

Craig, R. J. (1982). Personality characteristics of heroin addicts: Review of the empirical research 1976-1979. The International Journal of the Addictions, 63, 267-276.

Densen-Gerber, J., \& Rohrs, C. C. (1973). Drug-addicted parents and child abuse. Contemporary Drug Problems, 2, 683-696.

Deren, S. (1986). Children of substance abusers: A review of the literature. Journal of Substance Abuse Treatment, 3, 77-94.

Famularo, R., Kinscherff, R., \& Fenton, T. (1992). Parental substance abuse and the nature of child maltreatment. Child Abuse and Neglect, 16, 475-483.

Fanshel, D. (1975). Parental failure and consequences for children: The drug-abusing mother whose children are in foster care. American Journal of Diseases in Children, 65, 604612.

Fawzy, I. F., Coombs, R. H, \& Gerber, B. (1983). Generational continuity in the use of substances: The impact of parental substance use on adolescent substance use. Addictive Behaviors, 109-114. 
Gfroerer, J. (1987). Correlation between drug use by teenagers and drug use by older family members. American Journal of Drug and Alcohol Abuse, 13, 95-108.

Glantz, M. D., \& Pickens, R. W. (1993). Vulnerability to drug abuse: Introduction and overview. In M. D. Glantz \& R. W. Pickens (Eds), Vulnerability to drug abuse (pp. 114). Washington, DC: American Psychological Association.

Griffith, D., \& Freier, C. (1992). Methodological issues in the assessment of the motherchild interactions of substance abusing women and their children. NIDA Research Monograph, 117, 228-247.

Herjanic, B. M., Barredo, V. H., Herjanic, M., \& Tomelleri, C. (1979). Children of heroin addicts. The International Journal of the Addictions, 14, 919-931.

Herjanic, B., Herjanic, M., Wetzel, R., \& Tomelleri, C. (1978). Substance abuse: Its effects on offspring. Research Communications in Psychology, Psychiatry and Behavior, 3,6575.

Jastak, S., \& Wilkinson, G. S. (1984). The Wide Range Achievement Test-Revised. Wilmington, DE: Jastak Associates.

Jeremy, R. J., \& Bernstein, V. (1984). Dyads at risk: Methadone-maintained women and their four-month-old infants. Child Development, 55, 1141-1154.

Johnson, J. (1991). Forgotten no longer: An overview of research on children of chemically dependent parents. In T. M. Rivinus(Ed.), Children of chemically dependent parents (pp. 29-54). New York: Brunner.

Johnson, J. L., Boney, T. Y., \& Brown, B. S. (1991). Evidence of depressive symptoms in children of substance abusers. The International Journal of the Addictions, 25, 465-479.

Johnson. J. L.. \& Rosen, T. S. (1990). Difficult mothers of difficult babies: Mother-infant interaction in a multi-risk population. American Journal of Orthopsychiatry, 60, 281288.

Kandel. D. B. (1990). Parenting styles, drug use. and children's adjustment in families of young adults. Journal of Marriage and the Family, 52, 183-196.

Kccnan. E., Dorman. A., \& O'Connor. J. (1993). Six-year follow-up of forty-five pregnant opiate addicts. Irish Journal of Medical Science, 162, 252-255.

Khantzian. E. J. (1985). The self-medication hypothesis of addictive disorders: Focus on heroin and cocaine dependence. American Journal of Psychiatry. 142. 1259-1264.

Kovacs, M. (1983). The Children's Depression Inventory: A self-rated depression scale for school-aged youngsters. Unpublished manuscript, University of Pittsburg School of Medicine.

Kumpfer, K. L., \& DeMarsh, J. (1986). Family environmental and genetic influences on children's future chemical dependency. In S. Griswold-Ezekoye, K. L. Kumpfer, \& W. J. Bukosi (Eds.). Childhood and chemical abuse: Prevention and intervention (pp. 4991). New York: Haworth Press.

Lawson. M.S.. \& Wilson. G. S. (1980). Parenting among women addicted to narcotics. Child Welfare, 59, 67-79.

Lief, N. R. (1985). The drug user as a parent. The International Journal of the Addictions, 20, 63-97.

Luthar, S. S., Anton, S. F., Merikangas, K. R., \& Rounsaville, B. J. (1992). Vulnerability to substance abuse and psychopathology among siblings of opioid abusers. The Journal of Nervous and Mental Disease, 180, 153-161.

Maddux, J. F., Desmond, D. P., \& Costello, R. (1987). Depression in opioid users varies with substance use status. American Journal of Drug and Alcohol Abuse, 13, 375-385. 
Mayer, J.. \& Black. R. (1977). Child abuse and neglect in families with an alcohol or opiate addicted parent. Child Abuse and Neglect, 1, 85-98.

Mayes, L. C. (1995). Substance abuse and parenting. In M. H. Bornstein (Ed.), Handbook of parenting, Vol. 4 (pp. 101-125). Mahwah, NJ: Lawrence Erlbaum.

Murphy, J. M., Jellinek, M., Quinn, D., Smith, G., Poitrast, F. G., \& Gosko, M. (1991). Substance abuse and serious child mistreatment: Prevalence, risk, and outcome in a court sample. Child Abuse and Neglect, 15, 197-211.

Neville, R. G., McKellican, J. F., \& Foster, J. (1987). Children in the care of heroin users. Maternal and Child Health, 72,213-216.

Newcomb, M. D., \& Bentler, P. M. (1988). Consequences of adolescent drug use: Impact on the lives of young adults. London: Sage Publications.

Nichtern, S. (1973). The children of drug users. Journal of the American Academy of Child Psychiatry, 12, 24-31.

O'Connor, J. J., Stafford-Johnson, S., \& Kelly, M. G. (1988). A review of the characteristics and treatment progress of 45 pregnant opiate addicts attending the Irish National Drug Advisory and Treatment Centre over a two-year period. Irish Journal of Medical Science, 157, 146-149.

O'Dea, P. (1996). Management of the drug offender. Irish SocialWorker, 14, 18-20.

O'Higgins, K. (1996). Treated drug misuse in the Greater Dublin Area: A review of five years 1990-1994. Dublin: The Health Research Board.

O'Mahony, P. (1996). Criminal chaos: Seven crises in Irish criminal justice. Dublin: Round Hall, Sweet, \& Maxwell.

Peele, S. (1989). The diseasing of America: Addiction treatment out of control. Boston, MA: Houghton Mifflin Company.

Rabitte, P. (1996). First report of the Ministerial Task Force on measures to reduce the demand for drugs. Dublin: Department of An Taoiseach.

Regan, D. O., Ehrlich, S. M., \& Finnegan, L. P. (1987). Infants of drug addicts: At risk for child abuse, neglect, and placement in foster care. Neurotoxicologv and Teratology, 9, 315-319.

Rounsaville, B. J., Anton. S. F., Carroll, K., Budde, D.. Prusoff. B. A., \& Gavin, F. H. (1991). Psychiatric diagnosis of treatment-seeking cocaine abusers. Archives of General Psychiatry, 48, 739-745.

Rounsaville, B. J., \& Kleber. H. D. (1985). Psychotherapy/ counseling for opiate addicts: Strategies for use in different treatment settings. The International Journal of the Addictions, 20, 869-896.

Rounsaville, B. J.. Weissman, M. M., Kleber, H., \& Wilber, C. (1982). Heterogeneity of psychiatric diagnoses in treated opiate addicts. Archives of General Psychiatry, 39, 161166.

Rutter, M. (1990). Psychosocial resilience and protective mechanisms. In J. Rolf, A. S. Masten, D. Cichetti, K. H. Nuechterlin. \& S. Weintraub (Eds.). Risk and protective factors in the development of psychopathology (pp. 181-214). New York: Cambridge University Press.

Ryan, A., Magee, T.. Stafford-Johnson. S.. Griffin. E.. \& Kelly. M. G. (1983). The emergence of maternal drug addiction as a problem in Ireland 1981. Irish Medical Journal, 76, 86-89.

Rydelius, P. A. (1997). Annotation: Are children of alcoholics a clinical concern for child and adolescent psychiatrists of today? Journal of Child Psychology and Psychiatry, 38, 615-624. 
Sack, W. H., Seidler, J., \& Thomas, S. (1976). The children of imprisoned parents: A psychosocial exploration. American Journal of Orthopsychiatry, 46, 618-628.

Simons, R. L., \& Robertson. J. F. (1989). The impact of parenting factors, deviant peers, and coping style upon adolescent drug use. Family Relations, 38, 273-281.

Sowder, B. J., \& Burt, M. R. (1980). Children of heroin addicts: An assessment of health, learning, behavioral, and adjustment problems. New York: Praeger.

Speilberger, C. D. (1973). STAIC: Preliminary Manual for the State-Trait Anxiety Inventory for Children. Palo Alto, CA: Consulting Psychologists Press.

Tarter, R., Blackson, T., Martin, C, Leber, R., \& Moss, H. (1993). Characteristics and correlates of child discipline practices in substance abuse and normal families. American Journal of Addiction, 2, 18-25.

Tucker, M. B. (1979). A descriptive and comparative analysis of the social support structure of heroin addicted women. Addicted women: Family dynamics, self-perceptions, and support systems (pp. 37-76). Washington, DC: NIDA, Supt. of Docs., U.S. Government Printing Office.

Vorhees, C. V., \& Mollnow, E. (1987). Behavior teratogenesis: Long-term influences on behavior. In J. D. Osofsky (Ed.), Handbook of infant development (2nd edn.). New York: Wiley.

Wasserman, D. R., \& Levanthal, J. M. (1993). Maltreatment of children born to cocainedependent mothers. American Journal of Diseases in Children, 147, 1324-1328.

Weiss, R. D., Minn, S. M., Michael, J. L., \& Sollagub, A. C. (1986). Psychopathology in chronic cocaine abusers. American Journal of Drug and Alcohol Abuse, 12, 17-29.

Wellisch, D. K., \& Steinberg, M. R. (1980). Parenting attitudes of addict mothers. The International Journal of the Addictions, 15, 809-819.

Werner, E. E., \& Smith, R. S. (1992). Overcoming the odds: High risk children from birth to adulthood. Ithaca, NY: Cornell University Press.

Wilens, T. E., Biederman, J., Kiely, K., Bredin, E., \& Spencer, T. J. (1995). Pilot study of behavioral and emotional disturbances in the high-risk children of parents with opioid dependence. Journal of the American Academy of Child and Adolescent Psychiatry, 34, 779-785.

Williams, H., O'Connor. J.J., \& Kinsella. A. (1990). Depressive Clinicians guide to cocaine addiction (pp. 335-338). New symptoms in opiate addicts on methadone maintenance. Irish Journal of Psychology. 7, 45-6.

Wilson, G. S.. McCreary. R.. Kean.J..\& Baxter, C. (1979). The development of pre-school children of heroin addicted mothers: A controlled study. Pediatrics, 63, 135-141.

Ziedonis, D. M. (1992). Comorbid psychopathology and cocaine addiction. In T. R. Kosten \& H. D. Kleber (Eds.), Manuscript accepted 4 December 1997, York: Guilford Press.

Zuckerman. B.. Amaro, H.. Bauchner, H., \& Cabral, H. (1989). Depressive symptoms during pregnancy: Relationship to development of preschool children of heroin-addicted poor health behaviors. American Journal of Obstetrics and Gynecology, 160, 1107-1 111. 